\title{
The Impact of the COVID-19 Pandemic on the Anxiety of Adolescents in Québec
}

\author{
Julie Lane ${ }^{1} \cdot$ Danyka Therriault $^{1}$ (D) - Audrey Dupuis ${ }^{1} \cdot$ Patrick Gosselin $^{2}$. \\ Jonathan $\mathrm{Smith}^{3} \cdot$ Saliha Ziam ${ }^{4} \cdot$ Mathieu Roy $^{5} \cdot$ Pasquale Roberge $^{5} \cdot$ Marti Drapeau $^{6}$. \\ Pascale Morin $^{7} \cdot$ Felix Berrigan $^{7} \cdot$ Isabelle Thibault $^{8} \cdot$ Magali Dufour $^{9}$
}

Accepted: 24 September 2021 / Published online: 9 October 2021

(c) The Author(s), under exclusive licence to Springer Science+Business Media, LLC, part of Springer Nature 2021

\begin{abstract}
Background Several studies conducted since the beginning of the COVID-19 pandemic have shown its harmful effects on young people's mental health. In Québec and Canada, few studies have focussed on adolescents, and even fewer of these studies have examined this subject using a methodology that involved comparisons of data obtained before and during the pandemic, which is the purpose of this study.

Objective The objective of this study is to determine the impact of the COVID-19 pandemic on the anxiety of secondary 1 and 2 students in Québec, using data obtained before and during the pandemic.

Method Participants were 2990 French Canadian students in secondary 1 (grade 7) and secondary 2 (grade 8) in Québec. Two independent samples completed the questionnaires, one sample before the pandemic (fall 2019) and one sample during the pandemic (fall 2020). Their answers were subjected to descriptive analysis and multivariate analysis of variance.

Results Results show that the pandemic has had variable impacts on the student's mental health, with some of them reporting negative effects on their lives, others reporting no effect, and some reporting positive effect. However, the students surveyed during the pandemic generally reported more symptoms of generalized anxiety, and higher levels of test anxiety, fear of judgment and perfectionism than the ones surveyed before the pandemic.

Conclusions The discussion puts forward possible explanations for the results obtained, which contribute to a better understanding of young adolescents' experience during the COVID-19 pandemic. It also discusses the importance of developing interventions for adolescents affected by this pandemic.
\end{abstract}

Keywords Anxiety $\cdot$ Adolescence $\cdot$ COVID-19 pandemic

Danyka Therriault

danyka.therriault@usherbrooke.ca

Extended author information available on the last page of the article 


\section{Introduction}

\section{The COVID-19 Pandemic in Québec and Canada}

The year 2020 was marked by the COVID-19 pandemic. Québec declared a health emergency on March 13, leading to the closure of all schools across the province. Shortly after, between March 15 and 21, organised sports were put on hold and all gatherings were banned (Institut Nationale de Santé Publique [INSPQ], 2021). In the following summer, there was a partial loosening of some public health measures, although stricter measures were once again put in place when students returned to school in the fall. In January 2021, in response to the increase in the number of COVID-19 cases, the Government of Québec announced a second lockdown, but authorized students to return to class after the holidays, full-time for secondary 1 and 2 students (7th and 8th grade equivalent). These measures were then modulated according to the pandemic's evolution by region.

Pandemics and the associated quarantines can have substantial and wide-ranging consequences on the individuals, that can endure over time. High levels of stress can emerge given the sudden and important changes in people daily lives (Brooks et al., 2020). As for the COVID-19 pandemic, its consequences have been extensively documented in multiple studies and in various countries and include higher levels of psychological distress, anxiety, depression, sleep disorders, traumatic stress symptoms, suicidal ideation and substance abuse (Ammerman et al., 2020; Huang et al., 2020; Newby et al., 2020; Qiu et al., 2020; Wang et al., 2020). That said, relatively few studies have been conducted with adolescents in Canada, and more specifically in Québec. Given the heterogeneous nature of the evolution of the pandemic and of the measures put in place by the governments in response, this article focuses on Canada and Québec data.

In Québec and Canada, public health studies and surveys indicate that this pandemic has had significant personal implications, not to mention social and financial impacts. On the individual level, studies report a decrease in sleep time, and an increase in psychological distress, stress and anxiety, depressive symptoms, suicidal ideation, and alcohol and cannabis use (Best et al., 2020; Dozois \& Mental Health Research Canada, 2020; Généreux et al., 2020; INSPQ, 2020; Robillard et al., 2020). On the social level, there has been an increase in contact with immediate family members, but a decrease in contact with friends and in the quality of relationships with family and friends (Robillard et al., 2020). On the financial level, this has been a decrease in spending, but also a decrease in employment income (Robillard et al., 2020).

\section{The Impact of the Pandemic on the Mental Health of Adolescents in Québec and Canada}

Several sources have also suggested that the COVID-19 pandemic has had major effects on young people. Adolescence-with all that it entails - can make young people more likely to experience the negative effects of the lockdown and of other health measures associated with the pandemic. In particular, development during this period hinges on new experiences and social contact with peers, which have been drastically altered by the COVID19 pandemic (Cloutier \& Drapeau, 2008). Adolescents of every age can be affected, but young adolescents could be affected in a different way, as they also deal with their recent transition from elementary school (Eccles et al., 1993; Newman \& Newman, 2020). Eccles 
and al. (1993) add that many of the problems related to adolescence emerge during the early years as a result of the interaction between the developmental needs of adolescents and their environment. They also highlight the importance of the educational environment that can contribute to the developmental needs of adolescents and promote their continued growth (Eccles et al., 1993). However, they also argue that the transition from elementary school can lead to a bad fit between the needs of young adolescents and their environment. Their new school environment is notably characterized by a less personal and positive relationship with teachers, fewer opportunities for decision-making in class, more emphasis on academic performance, and more comparison with other students (Newman \& Newman, 2020). As a result, young adolescents face certain particular challenges with regards to their need for autonomy and control, for personal relationships with adults other than their parents, and for positive status in relation to their peers. This stage-environment misfit can have important consequences on these young adolescents' lives (Eccles et al., 1993; Newman \& Newman, 2020), and was negatively affected by the COVID-19 pandemic and its associated measures.

In this sense, the complete or partial closure of schools in Québec ${ }^{1}$ has (depending on the school) been marked by inconsistencies in the level of teaching, the subjects taught, and the presence of teachers themselves, all of which has contributed to a lack of motivation and socialization among high school students (Bergeron, 2020; Rousseau, 2020). Congruent with this, Smith et al. (2021) have suggested that a return to class after several months of distance learning is associated with an increased interest in learning. Studies also show that the pandemic has increased the amount of time that adolescents spend sleeping and on social media or technology in general and decreased their level of physical activity and time spent outdoors (Ellis et al., 2020; Moore et al., 2020). Regarding substance use, one study reports a significant increase in the number of days on which young people use alcohol or cannabis but reports a significant decrease in the number of young people who vape or use cannabis or alcohol in large quantities (Dumas et al., 2020).

Few studies from Québec and Canada have focussed solely on adolescents, but one of the main effects of the pandemic on the mental health of adolescents appears to be an increase in anxiety. Several studies have reported an increase in anxiety among young people during the COVID-19 pandemic (Ellis et al., 2020; Tardif-Grenier et al., 2021). Even before the pandemic, anxiety was on the rise among Québec teens. A survey completed by the Institut de la statistique du Québec (2018) found that 17\% of high school students in 2016-2017 had an anxiety disorder diagnosed by a healthcare professional, compared to 9\% in 2010-2011. This survey also found that anxiety is more prevalent in girls $(22.9 \%)$ than in boys $(11.8 \%)$, and that anxiety increases as students advance into the upper grade levels, although it decreases slightly between secondary 4 (grade 10) and 5 (grade 11). Anxiety has major effects on young people's lives, as it is associated to an increase in the risk of developing depressive symptoms, suicidal ideation, and drug or alcohol abuse, and a decrease in the ability to concentrate and in academic performance, adaptability, and social skills (Dumas, 2013; Turgeon \& Gosselin, 2015).

This section summarizes some of the work done specifically on anxiety in young people amid the COVID-19 pandemic in Québec and Canada, divided in two categories: scientific

\footnotetext{
${ }^{1}$ Few scientific articles have been published to date on the effects of COVID-19 on Canadians. As such, the data reported in this section are drawn from scientific articles, as well as from conference presentations or newspaper articles reporting comments made by healthcare researchers or professionals.
} 
studies, and surveys and polls. The scientific studies were peer-reviewed and used standardized measures, which surveys and polls did not.

\section{Scientific studies}

The Tardif-Grenier et al. study (2021) sought to determine the sociodemographic characteristics, habits during lockdown, and sources of support associated with the level of anxious or depressive symptoms in adolescents in Québec. The participants were 895 adolescents ( $74 \%$ female, $26 \%$ male) aged 12 to 17 ( $M=14.73$ years). They were invited to complete an online questionnaire through social media and by various partners in the province's education and social services networks. The scales used were the French version of the Center for Epidemiological Studies Depression Scale (Morin et al., 2011) to measure the presence and severity of symptoms of depression; the French version of the Screen for Child Anxiety Related Disorders-Revised (Martin \& Gosselin, 2012), to measure the symptoms of anxiety; and a questionnaire on sociodemographic characteristics (age, family composition, academic performance), habits during lockdown (schedule, sleep, use of technology, sports, schoolwork, and new hobbies), and sources of support (parents who work outside the home, parental support, teacher support). Results showed that girls reported more anxious and depressive symptoms than boys. Results also showed that students from an "intact" family (i.e., living with two parents) report higher levels of anxiety, as do those who spend less time on their cellphones. Students who report doing schoolwork, starting a new hobby, or having parents who work outside the home indicate lower levels of depressive symptoms. Students who report playing sports indicate higher levels of positive emotions.

The Ellis et al. study (2020) sought to determine the relationship between psychological adjustment and the stress associated with the COVID-19 pandemic in Canadian adolescents. The participants were 316 adolescents (76.4\% female, $21.9 \%$ male, $1.2 \%$ other) aged 14 to 18 ( $M=16.68$ years) who completed an online questionnaire. The questionnaire included the Brief Symptom Inventory (Derogatis \& Melisaratos, 1983) to measure depression; the Revised UCLA Loneliness Scale (Hays \& DiMatteo, 1987) to measure loneliness; and the Godin Leisure-Time Exercise Questionnaire (Godin, 2011) to document leisure and exercise. The researchers also investigated stress associated with COVID-19, the use of social media, and daily activities. The authors define this stress as the fear of COVID19 spreading, of being infected with COVID-19, and of the impact of health measures on school and social life. Results showed that overall, $43.1 \%$ of participants reported a high level of stress related to the COVID-19 pandemic, while $54.2 \%$ reported moderate stress, and $2.7 \%$ no stress. The participants reported a very high level of stress associated with the impact of the pandemic on their school year (71.7\%), on their contact with friends $(40.5 \%)$, and on family finances $(36.2 \%)$. The authors also found that girls reported more depressive symptoms and stress associated with COVID-19 than boys. The level of stress associated with COVID-19 also correlated positively with loneliness, the presence of depressive symptoms, time spent online with friends, watching the news, doing schoolwork, and on social media.

The Hawke et al. study (2020) also sought to examine mental health and substance use in Canadian adolescents during the COVID-19 pandemic. The participants were 622 adolescents or young adults $(62.5 \%$ female, $32.8 \%$ male, $4.6 \%$ other) aged 14 to 28 $(M=20.8$ years $)$. They were divided into two categories: a clinical sample $(n=276)$ and a population-based sample $(n=346)$. They were invited to complete an online questionnaire 
through their previous enrollment in studies led by the researchers. The instruments used were the CoRonavIruS Health Impact Survey (Merikangas et al., 2020), to retrospectively measure the emotional and behavioural response of young people to the pandemic; the Brief COPE (Carver, 1997), to measure adaptive strategies put in place; and the GAIN-SS (Dennis et al., 2006), to measure internalized or externalized issues related to substance use and violence. A questionnaire designed by the study investigators on strategies used by young people to maintain their well-being, and on the disruptions experienced in different spheres of their life was also used. Results showed a deterioration in the mental health of the participants, in particular among those in the population-based sample. The participants' main concerns were related to the risk of a family member contracting COVID-19, interruptions to school or work, and their mental health. The participants also cited some positive impacts of the COVID-19 pandemic, the most important being spending time with friends online, spending time with their pet, pursuing hobbies, and spending time with their family online.

\section{Surveys and Polls}

Several surveys and polls were also conducted among young people in Québec and Canada during the COVID-19 pandemic (Généreux et al., 2021; Maximum City, 2020, 2021). The Généreux et al. survey (2021) was conducted among 16,500 adolescents or young adults ( $57 \%$ female; $43 \%$ male) aged 12 to 25 , who filled out an online survey. Results showed that three times as many high school students who reported fair or poor mental health in January 2021, compared to January 2020 (30\% versus 11\%). The researchers point out that this deterioration in mental health extends from secondary 1 (grade 7) to secondary 5 (grade 11) and appears to increase as the students advance through the grade levels. The results also indicated that many high school students reported symptoms compatible with generalized anxiety disorder or major depression, namely $35 \%$ in secondary 1 (grade 7) and 2 (grade 8), and 50\% in secondary 3 (grade 9) to 5 (grade 11). Looking more closely at secondary 1 and 2, the results indicated an increase in symptoms compatible with generalized anxiety disorder between secondary 1 (23\%) and $2(27 \%)$, as well as an increase in symptoms compatible with major depression (from 27 to $34 \%$ ). Among the factors that negatively impacted the respondents' mental health, the authors report (1) the reduction in social, sports, and cultural activities, (2) the increase in screen time, and (3) the increase in online learning. This last point is more applicable to secondary 3 to 5 students, who had online classes $50 \%$ of the time, unlike secondary 1 and 2 students, who typically had no online classes.

The report prepared by Maximum City (2020) aimed to identify the behaviours, feelings, and opinions of Canadian children and adolescents during the COVID-19 pandemic. The participants were 616 children and adolescents aged 9 to 15, and their parents or legal guardians, who filled out an online survey in spring 2020. The results are divided into four main sections: (1) feelings and emotions, (2) activities, (3) school and learning, (4) people and relationships. With respect to feelings and emotions, the participants reported feeling more bored (34\%) and anxious (27\%), but also calmer (29\%) and happier (24\%). Although $77 \%$ of participants felt like they were missing out on important life events or moments, $26 \%$ felt that the COVID-19 pandemic had had some positive effects on their lives, such as more time with family and more time to pursue their interests. With respect to activities, the participants reported spending more time using technology (83\%), sleeping more (51\%), and spending less time being physically active (53\%). With respect to school and 
learning, the participants reported spending less time on schoolwork (53\%), and 32\% found schoolwork less stressful, while $30 \%$ found it to be more stressful. With respect to people and relationships, the participants felt like the amount of time they were spending with family was just right (71\%), but that they were not spending enough time with their friends (38\%). A follow-up suervey done in fall 2020 showed that students who participated in school online or both online and in person, or who were homeschooled, reported more boredom, fatigue, loneliness, sadness, and worries compared to those who attended school in person. However, they reported feeling less frustrated, as well as calmer and more in control (Maximum City, 2021).

As a whole, these studies, surveys, and polls show that the COVID-19 pandemic had major effects on adolescents in Québec and Canada. Among the reported consequences, some stand out, including an increase in anxious and depressive symptoms (Ellis et al., 2020; Généreux et al., 2021; Tardif-Grenier et al., 2021). The studies also showed that girls report higher levels of anxiety and depression than boys (Ellis et al., 2020; Tardif-Grenier et al., 2021), and that anxiety seems to increase as the students advance through the grade levels (Généreux et al., 2021). Other associated factors include worries about the school year, worries about family finances, worries about COVID-19, lack of contact with friends, reduction of sports and cultural activities, increased time spent on social media and in online classes, in watching the news, as well as an increase in depressive symptoms (Ellis et al., 2020; Hawke et al., 2020). However, the studies also show that for some adolescents, the COVID-19 pandemic had positive effects, such as more time spent with family, time to pursue their interests and play sports (Hawke et al., 2020; Maximum City, 2020; TardifGrenier et al., 2021).

\section{The Agility of Studies and Surveys Amid the Pandemic and Their Biases}

These studies and survey show agility, as their authors were able to quickly take steps to identify the impacts of the pandemic and the lockdown on youth, with the goal of influencing mental health policies and services. This agility was seen in various places around the world, as the pandemic complicated the process of evidence-informed decision-making (EIDM), not to mention studies and syntheses surrounding EIDM (Munn et al., 2020). Because of the virus's extremely rapid spread, the enormous burden of morbidity and mortality, and the major implications for health system resources (Roche et al., 2020), important decisions had to be made in haste. This situation has greatly encouraged decisionmakers to rely on evidence (Munn et al., 2020) in order to reduce the risk of transmission and limit mortality. Researchers were very responsive, and many adjustments to research protocols in order to quickly collect and provide rapid access to data.

However, some biases can be observed, which may have influenced the results obtained. The Goldberg typology (2000) presents two broad categories of bias: selection bias and measurement bias. ${ }^{2}$ It is important to be aware of these biases in order to interpret the results of those studies and to try to limit these biases in further studies. In studies, surveys, polls, and media coverage on the topic, certain methodological

\footnotetext{
${ }^{2}$ Selection bias is defined as a bias that can lead to "the subjects actually observed in the survey not constituting a group that is representative of the study populations" [TRANSLATION] (Goldberg, 2000, p. 153). A measurement bias is defined as the set of "systematic errors that can be introduced during the measurement of the phenomena considered in the subjects enrolled in the study" [TRANSLATION] (Goldberg, 2000, p. 156).
} 
choices raise questions in terms of limits or bias. Thus, a limit can be observed in relation to social-media recruiting, which can attract individuals with specific profiles, thereby biasing the results. Recruiting a sample of volunteers online can also contribute to the risk of bias because, despite the advantages of this recruitment method, it also raises questions about the representativeness of the sample and the quality of the responses obtained (Frippiat \& Marquis, 2010). Moreover, some of the sources consulted used non-standardized instruments for their data collection, which may have introduced a measurement bias. It also appears that only one survey used a methodology that compares data obtained before and during the pandemic. While this does not represent a bias in and of itself, it does limit the conclusions that can be drawn regarding the impact of the COVID-19 pandemic on the mental health of young people.

The studies also appear to focus on older adolescents, rather than those between the ages of 12 and 14. Only two of the surveys and polls included data from students aged 14 and under. The Généreux et al. survey (2021) focused on young people aged 12 to 17 and showed that psychological distress increases as students advance through the grade levels. The report prepared by Maximum City (2020) focuses on young people age 9 to 15. Older students are not included, since the authors assumed that they are likely to have different experiences, in particular, regarding paid work and planning for post-secondary studies. The authors report no difference between the data collected from participants aged 14 and under and from those over the age of 14. This population seems to be under studied, despite the particularities in their situation, having recently transitioned from elementary to high school (Eccles et al., 1993).

Therefore, the specific objectives of this article are to: (1) Document the impact of the COVID-19 lockdown on the well-being and mental health of secondary 1 and 2 students in Québec; (2) Document the impact of the COVID-19 pandemic on various dimensions related to the anxiety felt by these students, by comparing data collected before and during the COVID-19 pandemic from two independent samples, while examining the moderating effect of the adolescent's gender and grade level. On an empirical basis, our hypotheses are as follow: (1) The COVID-19 pandemic and its associated measures will have a negative effect on anxiety and depressive symptoms of secondary 1 and 2 students; (2) Girls will report higher levels of anxiety and depressive symptoms than boys; (3) Secondary 2 students will report higher levels of anxiety and depressive symptoms than secondary 1 students.

\section{Methodology}

The data were collected as part of the evaluation of the HORS-PISTE program, an initiative of the RBC Centre for Academic Expertise in Mental Health (Universite de Sherbrooke). The objective of this program is to lessen the risk factors related to anxiety and to strengthen the protection factors through the promotion of mental health and the development of psychosocial skills. As part of the process to evaluate the implementation and effects of this prevention program, participants are asked to complete an evaluation protocol consisting of a series of standardized questionnaires, once during a pre-test, and again during a post-test. The data used for this study come from the pretests in 2019-2020 and 2020-2021. 


\section{Participants and Procedures}

The data were collected at two points in time, from two separate samples. The initial data collection took place before the COVID-19 pandemic, between October and December 2019. Participants included 1,610 students (48.9\% female, $49.3 \%$ male) in secondary 1 (grade 7 ) and 2 (grade 8 ), with an average age of 12.66 years $(S D=0.84)$. These students were in 12 high schools located throughout three major regions of Québec (Estrie, Montérégie, and Mauricie-Centre-du-Québec). The second data collection took place during the COVID-19 pandemic, between October and December 2020. Participants included 1,380 students (49.8\% female, $49.9 \%$ male) in secondary 1 (grade 7) and 2 (grade 8), with an average age of 12.59 years $(S D=0.74)$. These students came from 11 high schools located throughout three major regions of Québec (Estrie, Montérégie, and Mauricie-Centre-duQuébec). In both samples, about $85 \%$ of students reported that their parents were born in Canada, which suggests that few participants are first- or second-generation immigrants.

The data were collected in the classroom, using a paper or online questionnaire (at the school's discretion), under the supervision of a teacher or staff member. $70 \%$ of the sample completed the written form. To ensure a standardized procedure, teachers and staff members were given instructions about how to administer the questionnaires. Parental consent was obtained for students under 14, while those 14 could consent for themselves when filling out the questionnaires. The participants did not receive any financial compensation. The evaluation protocol and the student recruitment process were used to try to reduce some of the measurement and selection biases mentioned earlier. This study was approved by Université de Sherbrooke's education and social sciences ethics committee.

\section{Scales}

The student evaluation protocol comprised several measurement instruments. In keeping with the objective to document the impact of the COVID-19 lockdown on the well-being and mental health of secondary 1 and 2 students in Québec, a question was added during the fall 2020 data collection to measure the effects of the COVID-19 lockdown. Each participant was asked to select the statement, from among the following, that best describes their perception of the effect that the pandemic-related lockdown had on their well-being and mental health: "Positively affected my well-being and mental health", "Did not affect my well-being or mental health", and "Negatively affected my well-being and mental health".

In keeping with the objective to document the impact of the COVID-19 pandemic on various dimensions related to the anxiety felt by these students, by comparing data collected before and during the COVID-19 pandemic from two independent samples, while examining the moderating effect of the adolescent's gender and grade level, several measurement instruments were used to document the impact of the COVID-19 pandemic on various dimensions related to anxiety. Some of these instruments served to document the students' symptoms of anxiety and their effects, while others were used to measure variables related to anxiety, such as fear of being judged, perfectionism, self-esteem. feelings of depression, problematic internet use, etc.

Symptoms of anxiety associated with various disorders (panic disorder, generalized anxiety disorder, separation anxiety disorder, social anxiety disorder, obsessive-compulsive disorder, and post-traumatic stress disorder) were measured using subscales from the 
French version of the Screen for Child Anxiety Related Disorders Revised (Martin \& Gosselin, 2012; Muris et al., 1998). This questionnaire includes a total of nine subscales rated using a three-point scale $(0=$ almost never, $1=$ sometimes, $2=$ often $)$. In this study, six of the nine scales were used: panic disorder, which includes 7 items ("When I feel frightened, it is hard to breathe"); generalized anxiety disorder, which includes 7 items ("I worry about things working out for me"); separation anxiety disorder, which includes 7 items ("I worry about sleeping alone"); social anxiety disorder, consisting of 4 items ("I feel nervous with people I don't know well"); obsessive-compulsive disorder, which includes 5 items ("I want things to be in order or neatly arranged"); and post-traumatic stress disorder, which includes 4 items ("I have flashbacks about something bad that happened to me"). This scale has good convergent and divergent validity (Monga et al., 2000). The French version of the tool also has good psychometric properties, in particular in terms of convergent and criterion validity, and reliability (Martin \& Gosselin, 2012). The Cronbach's alphas obtained in this study indicate satisfactory internal consistency for most of the scales used (panic disorder: $\alpha=0.84$ (2019)/0.83 (2020); generalized anxiety disorder: $\alpha=0.84$ (2019)/0.83 (2020); separation anxiety disorder: $\alpha=0.68$ (2019)/0.69 (2020); social anxiety disorder: $\alpha=0.78$ (2019)/0.83 (2020); obsessive-compulsive disorder: $\alpha=0.48$ (2019)/0.51 (2020); and post-traumatic stress disorder: $\alpha=0.78(2019) / 0.76(2020)){ }^{3}$

Test anxiety was measured using the French version of the Test Anxiety InventoryShort form (Taylor \& Deane, 2002). This tool, comprised of five items ("During tests I feel very tense"), is used to measure the state of mind of adolescents and post-secondary students during tests. For each item, the respondent must indicate, on a four-point Likert scale ( $1=$ almost never, $2=$ sometimes, $3=$ often, $4=$ almost always $)$, the degree to which each statement applies to them. This short version has good validity and reliability (Taylor \& Deane, 2002). For this study, the Cronbach's alpha obtained indicate good internal consistency $(\alpha=0.82(2019) / 0.85(2020))$.

Fear of being judged by others was measured using the French version of the Fear of Negative Evaluation scale (Monfette et al., 2006; Watson \& Friend, 1969). This questionnaire is comprised of 12 items (e.g., "I am afraid others will criticize me") which are scored using a Likert scale from 1 (does not describe me at all) to 5 (describes me extremely well). The psychometric properties of the French version were evaluated with adolescents; the scale has good internal consistency. In this study, a committee of three experts and a research assistant evaluated the relevance of the items with respect to the presumed understanding of the young people; this led to the removal of 5 items that were deemed problematic. The version used in this study is therefore comprised of seven items and has good internal consistency ( $\alpha=0.85$ (2019)/0.86 (2020)).

Perfectionism was measured using the abridged French version of the Child-Adolescent Perfectionism Scale (Dourez \& Hénot, 2013; Flett et al., 2000). Only one scale, measuring self-oriented perfectionism, was used in this study, for a total of seven items ("I try to be perfect in everything I do") evaluated on a Likert scale ( $1=$ not at all true of me to $5=$ very true of me). The Cronbach's alpha obtained for this scale in this study indicates good internal consistency ( $\alpha=0.88$ (2019)/0.86 (2020)).

\footnotetext{
3 According to the markers proposed by Hinton et al. (2014), a Cronbach's alpha less than 0.50 indicates low internal consistency, an alpha greater than or equal to 0.50 and less than 0.70 indicates moderate internal consistency, an alpha greater than or equal to 0.70 and less than 0.90 indicates good internal consistency, and an alpha greater than 0.90 indicates excellent internal consistency.
} 
Self-esteem was measured using the French version of the Rosenberg Self-Esteem Scale (Vallières \& Vallerand, 1990). This tool, comprised of ten items ("On the whole, I am satisfied with myself"), was used to measure the adolescent's perception of their own value. For each statement, the adolescent had to indicate their level of agreement on a 4-point Likert scale $(1=$ strongly disagree to $4=$ strongly agree). Again, the Cronbach's alpha obtained for this tool indicated excellent internal validity $(\alpha=0.89(2019) / 0.90(2020))$.

Feelings of depression were measured using the short French version of the Children's Depression Inventory (Kovacs, 1985). This questionnaire is comprised of 10 items ("Things bother me once in a while"), each presented as three statements that best describe the respondent's situation in the previous two weeks. In this study, the Cronbach's alpha obtained indicated good internal consistency $(\alpha=0.84(2019) / 0.82(2020))$.

Problematic internet use was measured using the French version of the Compulsive Internet Use Scale (Meerkerk et al., 2009). Nine items were used in this study. These items were proposed by a researcher specialized in this field. On a six-point Likert scale $(1=$ never to $5=$ very often; $6=$ not applicable), the respondent had to indicate to what extent each item ("I am short of sleep because of the internet") applies to them. This nineitem version demonstrated good internal consistency in this study $(\alpha=0.84(2019) / 0.85$ (2020)).

The Cognitions reliées à l'anxiété généralisée pour enfants questionnaire (CAG; Gosselin, 2007) was used to measure intolerance to uncertainty, negative attitude when faced with problems, and cognitive avoidance. This questionnaire is comprised of 16 items (e.g., "When something scares me, I force myself to think about happy things") evaluated on a Likert scale $(1=$ not at all to $3=a$ lot $)$. In this study, the Cronbach's alphas indicated satisfactory internal consistency ( $\alpha=0.66$ to 0.82 (2019)/0.70 to 0.81 (2020)).

The impact of anxiety on the lives of adolescents was measured using the Child/Adolescent Anxiety Impact Scale (Langley et al., 2004). This self-reported tool, comprised of 27 items, is used to measure the impact of anxiety symptoms on a child's psychosocial adjustment. It evaluates the impact on three major dimensions: school activities, social activities, and family and home activities. In this study, only the total score was used because of the strong correlations observed between these three scales. For each item, based on a fourpoint Likert scale $(0=$ not at all to $3=$ a lot $)$, the adolescent had to rate their degree of difficulty in accomplishing each activity ("Getting to school on time") because of their anxiety symptoms over the past month. In the samples used for this study, the tool's internal consistency was excellent $(\alpha=0.94(2019) / \alpha=0.94$ (2020)).

\section{Data analysis}

All statistical analyses were completed using IBM's SPSS (Statistical Package for Social Sciences) software v.25 (2017). First, descriptive statistics were calculated for the question on the effect of the lockdown on well-being and mental health, to which the participants in the fall 2020 cohort were asked to respond. Second, descriptive statistics for all other variables of interest were calculated for the fall 2019 cohort and then for the 2020 cohort. A multivariate analysis of variance (MANOVA) was completed to examine the differences between the 2019 and 2020 data. A total of 15 variables were included in the analysis: panic disorder, generalized anxiety disorder, separation anxiety disorder, social anxiety disorder, post-traumatic stress disorder, test-related anxiety, fear of judgment by others, perfectionism, feelings of depression, self-esteem, problematic internet use, intolerance to uncertainty, negative attitude faced with problems, 
Table 1 Descriptive statistics-Effect of the lockdown on students' well-being and mental health

\begin{tabular}{lllllll}
\hline Effect of lockdown & Boys $\%$ & & \multicolumn{2}{l}{ Girls $\%$} & \multicolumn{3}{c}{ Total \% } \\
\hline Positively affected my well-being and mental health & Sec. 1 & 12.2 & Sec. 1 & 15.8 & Sec. 1 & 13.8 \\
& Sec. 2 & 16.5 & Sec. 2 & 13.5 & Sec. 2 & 13.8 \\
& Total & 13.8 & Total & 15.0 & Total & 14.4 \\
Did not affect my well-being or mental health & Sec. 1 & 72.2 & Sec. 1 & 60.9 & Sec. 1 & 66.4 \\
& Sec. 2 & 62.7 & Sec. 2 & 50.4 & Sec. 2 & 55.6 \\
& Total & 68.6 & Total & 56.7 & Total & 62.1 \\
Negatively affected my well-being and mental health & Sec. 1 & 15.6 & Sec. 1 & 23.4 & Sec. 1 & 19.7 \\
& Sec. 2 & 20.8 & Sec. 2 & 36.1 & Sec. 2 & 29.4 \\
& Total & 17.6 & Total & 28.3 & Total & 23.5 \\
\hline
\end{tabular}

cognitive avoidance, and impact of anxiety on activities. The obsessive-compulsive disorder scale was not included in the analyses because of the poor internal consistency of the scale. The year of data collection, grade level, and gender effects were included as main effects, as were the year*grade level and year*gender interaction effects, in order to examine the moderating effect of the adolescent's grade and gender on the differences observed between the two measurement points. When year*grade level or year*gender interaction effects were observed, ANOVAs were done to understand the moderating effect observed. The Wilks' lambda test was used to confirm that significant differences were observed between the groups.

\section{Results}

The objectives were to: (1) Document the impact of the COVID-19 lockdown on the well-being and mental health of secondary 1 and 2 students in Québec; (2) Document the impact of the COVID-19 pandemic on various dimensions related to the anxiety felt by these students, by comparing data collected before and during the COVID-19 pandemic from two independent samples, while examining the moderating effect of the adolescents' gender and grade level.

\section{Impact of the COVID-19 Lockdown}

The data analysis indicates that in fall $2020,14.4 \%$ of participants reported that the lockdown had a positive effect on their well-being and mental health, compared to $23.5 \%$ who reported a negative effect. The other participants $(62.1 \%)$ reported that the lockdown had no effect on their well-being or mental health. If we compare the results between secondary 1 (grade 7) and secondary 2 (grade 8 ) students (see Table 1), we see that more secondary 2 students reported that the lockdown negatively affected their well-being and mental health compared to secondary 1 students $(29.4 \%$ vs. $19.7 \%)$. More girls than boys $(28.3 \%$ vs. $17.6 \%)$ were also likely to report that the lockdown negatively affected their well-being and mental health. 


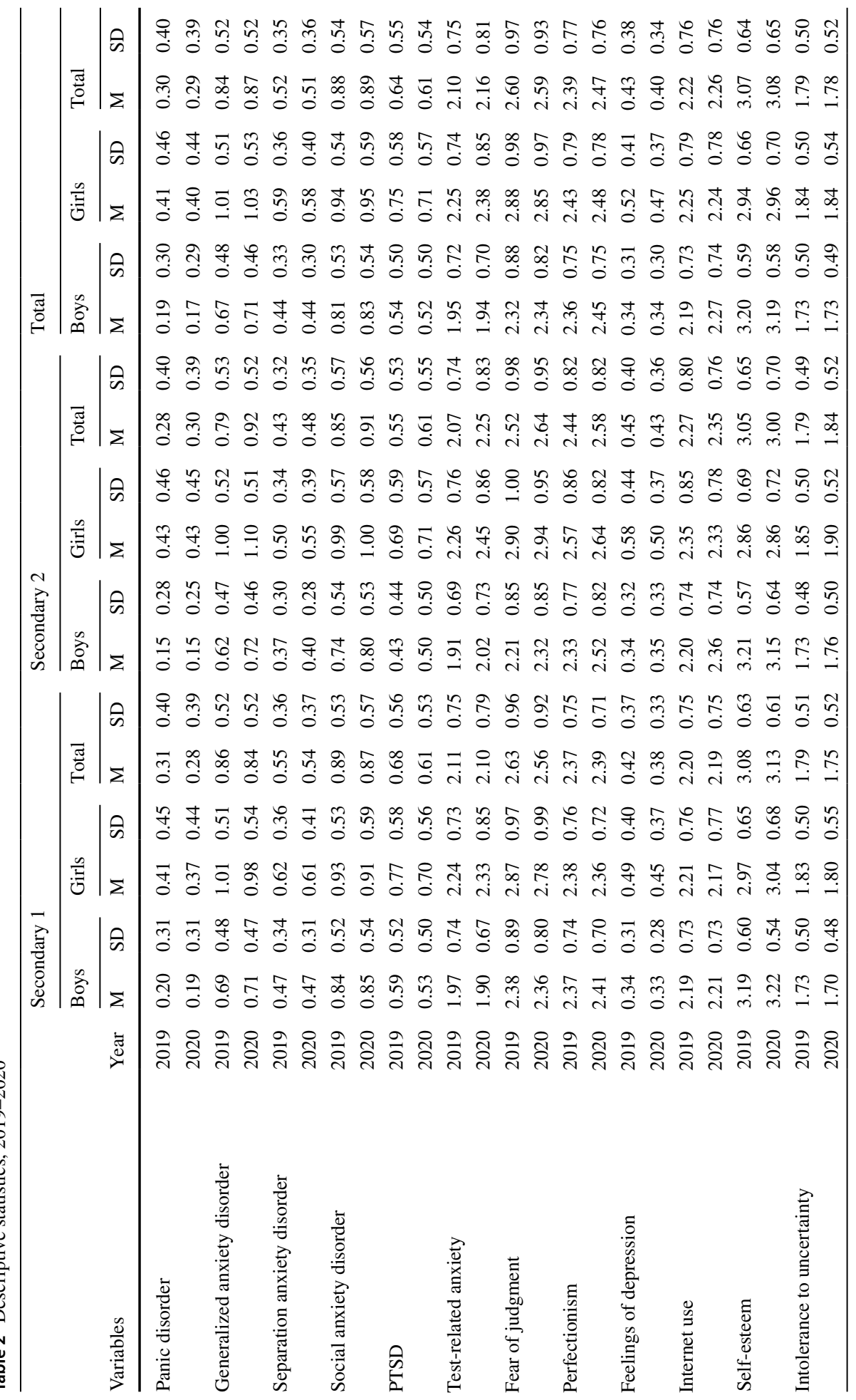




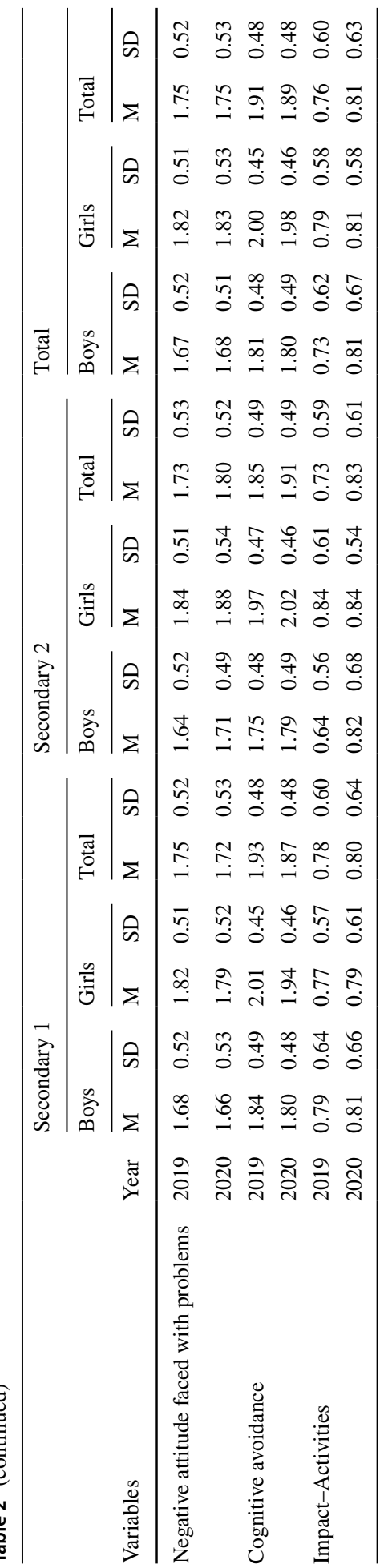




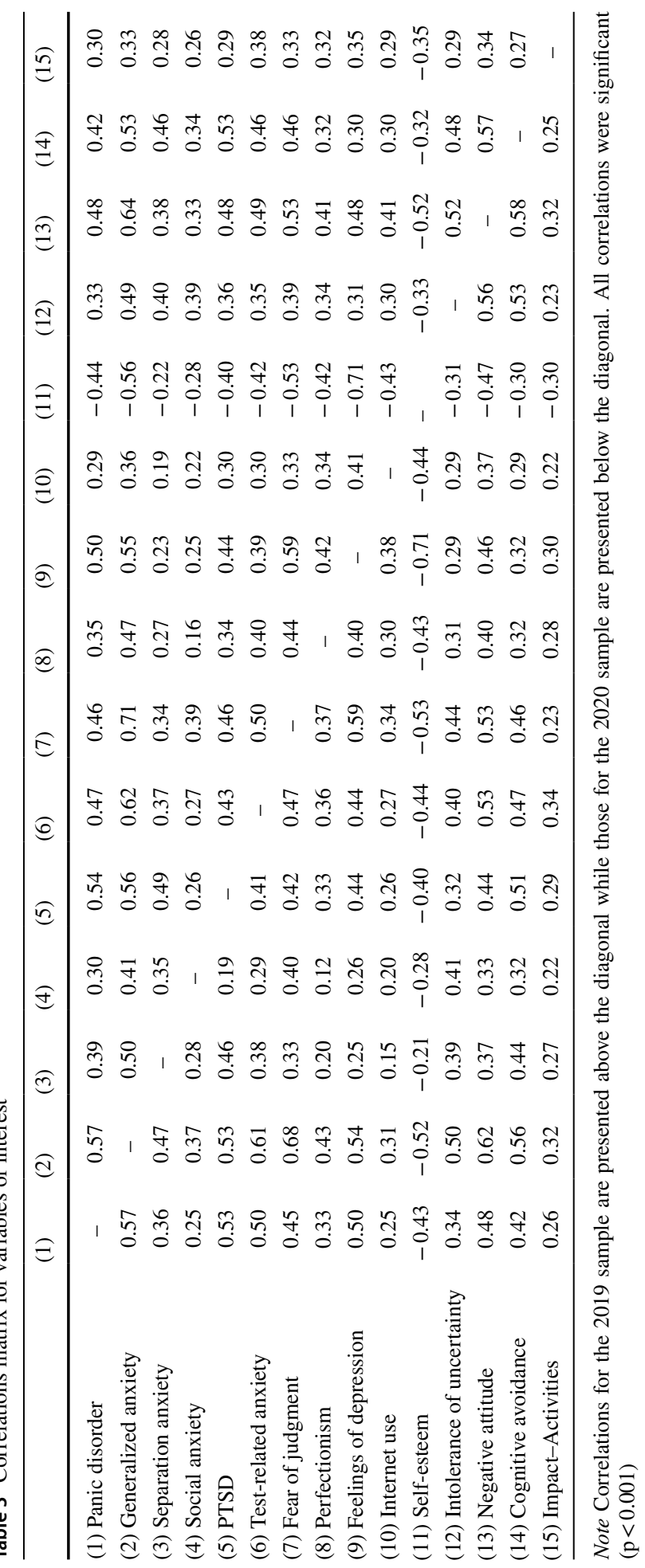




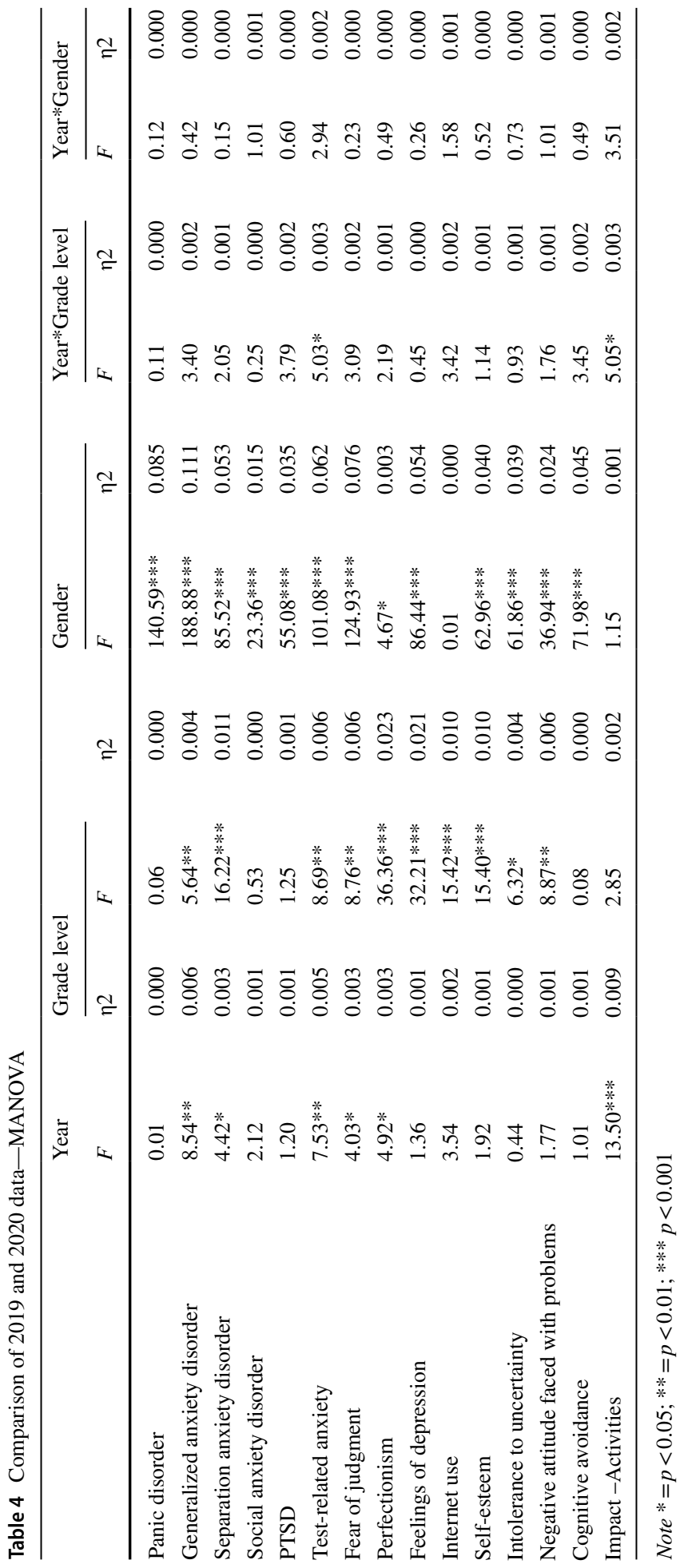




\section{Comparison of Data Before and During the COVID-19 Pandemic}

The descriptive statistics for each of the variables of interest and the correlations matrix are presented in Tables 2 and 3.

The results of the MANOVA are presented in Table 4. First, the results of the Wilks' lambda multivariate test show a significant effect of the year variable $(F=1.77 ; p<0.034$; $\eta 2=0.017)$. The examination of univariate effects shows several significant differences between the data collected in fall 2019 and those collected in fall 2020. First, the results indicate that, compared to students surveyed before the pandemic (fall 2019), those surveyed during the pandemic (fall 2020) reported significantly more symptoms of generalized anxiety $(F=8.54, p=0.004)$, and higher levels of test anxiety $(F=7.53 p=0.006)$, fear of judgment by others $(F=4.03 p=0.045)$ and perfectionism $(F=4.92, p=0.027)$. Students surveyed in 2020 also reported significantly higher levels of interference of the anxiety in their activities $(F=13.50 p<0.001)$. Finally, the results show that the students surveyed in 2020 reported slightly fewer symptoms of separation anxiety $(F=4.42 p=0.036)$ compared to those surveyed in 2019 . However, the effects observed are very small $(\eta 2<0.009)$. Finally, no significant difference was observed between the 2019 and 2020 data for the symptoms of panic disorder, social anxiety disorder, post-traumatic stress disorder, feelings of depression, internet use, self-esteem, intolerance to uncertainty, negative attitude faced with problems, and cognitive avoidance $(p>0.05)$.

The results of the Wilks' lambda multivariate test show that the year*grade level interaction effect and the year*gender interaction effect were not significant $(F=0.89 ; p=0.574$ / $F=1.07 ; p=0378$ ).

\section{Discussion}

The results of our study allow us to qualify the impacts of the COVID-19 lockdown on students by focusing on the pandemic's highly variable effects on them. While some students reported that the lockdown negatively affected their well-being and mental health, most reported no effect, and some reported a positive effect on their well-being and mental health. Therefore, we can conclude that the lockdown affected the students to varying degrees. These variable effects might be explained by various moderators. Indeed, some studies that have looked at the effects of natural disasters on young people's mental health have shown that certain pre-disaster aspects can moderate this effect, notably the quality of the parent-child relationship, the parental behaviors (Costa et al., 2009) or pre-existing anxiety symptoms (Weems et al., 2012). The study by Weems et al., (2012) also suggests that effect of disasters on young people's anxiety symptoms could be explained, at least in part, by TV viewing, which could be a plausible hypothesis in the context of the highly mediatized COVID-19 pandemic.

Our results also help to characterize the impacts of the COVID-19 pandemic on various dimensions related to anxiety, by comparing data collected before and during the COVID19 pandemic. In fact, the results show that no significant difference was observed between the 2019 and 2020 data for symptoms related to several anxiety disorders (panic disorder, separation anxiety disorder, social anxiety disorder, post-traumatic stress disorder) and for other dimensions related to anxiety (feelings of depression, internet use, self-esteem, intolerance to uncertainty, negative attitude faced with problems, cognitive avoidance). They 
also show that the negative impact pertains more to the differences observed in the symptoms of generalized anxiety, test-related anxiety, and the impact of anxiety on the young people's lives. How can these nuances in impacts, which do not show up in the other surveys and studies, be explained?

\section{Possible Explanations for the Effects of the COVID-19 Pandemic on Young People}

These results can likely be explained by the fact that the subjects are younger. The results of our study show that older students appear to be more affected by the impacts of the COVID-19 lockdown. In fact, more secondary 2 students than secondary 1 students report that the lockdown negatively affected their well-being and mental health. These results are in line with the survey by Généreux et al. (2021), which shows an increase in symptoms compatible with generalized anxiety disorder and major depression as students advance through the grade levels, including in between secondary 1 and 2 . These results are also consistent with the survey conducted by the Institut de la statistique du Québec (2018) prior to the COVID-19 pandemic, which shows that mental health and anxiety issues increase throughout high school, but decrease slightly between secondary 4 and 5 .

The results of our study also show that girls appear to be more affected by the impacts of the COVID-19 lockdown. In this regard, more girls than boys report that the lockdown negatively affected their well-being and mental health. These results are consistent with several results discussed above, which show that girls report more symptoms of stress, anxiety, and depression associated with COVID-19 (Ellis et al., 2020; Tardif-Grenier et al., 2021) or severe psychological distress associated with the pandemic (Clermont, 2020), when compared with boys. Note that the studies cited do not suggest possible explanations for these differences, but that girls are typically better at recognizing the symptoms of anxiety than boys, given their higher levels of emotional intelligence (Fernández-Berrocal et al., 2012). However, this result could also be explained by the fact that girls place a high value on friendships during adolescence and the social support they provide. Moreover, a study by Ohannessian et al. (2017) found that girls would generally be more sensitive to stressors associated with their interpersonal relationships. In this regard, the pandemic context may have been a significant stressor in terms of social relationships for adolescents, since they were deprived of the majority of their social contacts. Thus, it is possible that the negative impacts were greater for girls in this context.

Although the effects of the pandemic observed in this study are not as alarming as those reported in several recent surveys and studies, the lockdown has clearly had negative effects on a certain proportion of students, in particular in secondary 2 , and there is a pressing need to identify solutions to help the adolescent population to thrive and develop to their fullest potential given the circumstances. The differences observed between the 2019 and 2020 data in terms of symptoms of generalized anxiety could be explained by the frequent reversals in public health rules applicable in the various environments frequented by adolescents, which certainly amplifies the stressors the adolescents are exposed to (Imran et al., 2021; YoungMinds, 2020, 2021). These stressors played a role in upsetting the sometimes already delicate balance in some adolescents, who lack the inner resources to adapt to the challenges presented by this unprecedented situation. Not surprisingly, there is a significant difference between data collected before and during the pandemic in terms of the impact of symptoms of anxiety on adolescents' functioning in their school, social, and family activities, given that all their habits have been disrupted by the pandemic. Moreover, since the start of the 2020 school year, principals and teachers have placed strong emphasis 
on academic remediation, which likely plays a role in the difference observed in the testrelated anxiety and perfectionism seen in this study.

\section{Practical Outcomes, Strengths, and Limitations of the Study}

These nuanced results can also likely be explained, in part, by the data collection methodology, which is seen here as a strength, since it helps prevent certain biases, including a selection bias. In fact, the methodology used in this study implies that all students already enrolled in the HORS-PISTE program were invited to participate. This study avoids recruiting volunteers solely through social media, which reduces the risk of attracting certain subjects with specific profiles and provides a sample that is more representative. It also provides a good sample size, which tends to promote representativeness and increase the statistical power. Moreover, since the initial research does not directly address the impact of the COVID-19 pandemic on young people, but rather the effects of the HORS-PISTE program, this may have reduced the risk of a subjective bias (Goldberg, 2000), where the formulation of questions or the emphasis on the impact of the COVID-19 pandemic could influence responses in the desired direction. It is possible that participants' responses could be influenced by a study with a title that emphasizes the impact of the pandemic.

The methodology used also avoids certain measurement biases. All the questionnaires used have acceptable or good psychometric qualities, leaving little room for interpretation of the participants' responses. Another strong point of the methodology used is that it compares the data obtained during the COVID-19 pandemic with the data obtained using the same protocol, but before the pandemic. Linking these changes to the pandemic remains a challenge, given the observational nature of the study and the use of two distinct samples. Nevertheless, the methodology used makes it possible to more precisely and accurately determine the impact of the pandemic on the mental health of youth in Québec, through a comparison with previous data obtained using the same research protocol.

As such, this study provides a nuanced portrait of the impact of the pandemic on students in secondary 1 and 2, a population that was under studied compared to older adolescents, despite the fact that their recent transition from elementary school could have created some particularities in their situation (Eccles et al., 1993). Considering that the COVID-19 pandemic has had a major impact on the mental health of adolescents, and that it is likely to have longer-term repercussions, it appears the results can be used to better target interventions aimed at young people in particular, given the differences established between the groups (e.g., the difference between girls and boys). Globally, the results obtained contribute to a better understanding of the reality of young people amid this unprecedented situation.

The results of this study should be interpreted with certain limitations in mind. First, it is important to point out the cross-sectional nature of the design. In fact, although the data were collected at two different times, in fall 2019 and fall 2020, different students were surveyed each time. Therefore, we cannot conclude on an increase in symptoms or the associated risk factors. Moreover, all data were collected from the adolescents themselves, through questionnaires. A multi-respondent and multi-method approach would have no doubt contributed to the independence of observations and to greater validity. The fact that $85 \%$ of participants indicated that their parents were born in Canada suggests that few of them are the children of first- or second-generation immigrants; it might have been appropriate to collect more information on this aspect, as immigrants' particularities can have an impact on their reported mental health (Szaflarski et al., 2017). Moreover, in order to 
develop a better understanding of the differences observed in this study, in particular on lockdown's impact on the well-being of young people, it could be interesting to determine whether the young people who report a negative effect share certain characteristics that would explain this effect.

\section{Conclusion}

Our study methodology led to a better understanding of the impacts of the COVID-19 lockdown on students and will help to better target interventions that can be put in place quickly to help certain young people.

Funding This research was made possible through the financial support of the Public Health Agency of Canada's Mental Health Promotion Innovation Fund and the Réseau universitaire intégré de santé et de services sociaux de l'Université de Sherbrooke (RUISSS).

Availability of data and material Data is conserved by the Centre RBC d'expertise universitaire en santé mentale.

\section{Declarations}

Conflicts of interest No potential conflict of interest or competing interest was reported by the authors.

Ethics approval This study was approved by Université de Sherbrooke's education and social sciences ethics committee.

Consent to participate Informed consent was obtained from all individual participants included in the study or their legal guardians.

\section{References}

Ammerman, B. A., Burke, T. A., Jacobucci, R., \& McClure, K. (2020). Preliminary investigation of the association between COVID-19 and suicidal thoughts and behaviors in the U.S. PsyArXiv preprints. https://doi.org/10.31234/osf.io/68djp

Bergeron, J. (2020). La motivation et l'engagement [Conference session]. "Les jeunes face aux conséquences de la COVID-19" webinar. http://www.chairejeunesse.ca/node/1171

Best, L. A., Law, M. A., Roach, S., \& Wilbiks, J. M. P. (2020). The psychological impact of COVID-19 in Canada: Effects of social isolation during the initial response. Canadian Psychology, 62(1), 143-154. https://doi.org/10.1037/cap0000254

Brooks, S. K., Webster, R. K., Smith, L. E., Woodland, L., Wessely, S., Greenberg, N., \& Rubin, G. J. (2020). The psychological impact of quarantine and how to reduce it: Rapid review of the evidence. Lancet, 395(10227), 912-920. https://doi.org/10.1016/S0140-6736(20)30460-8

Carver, C. S. (1997). You want to measure coping but your protocol's too long: Consider the brief COPE. International Journal of Behavioral Medicine, 4(1), 92.

Clermont, C., Bergeron, S., Dubois-Bouchard, C., Attard, V., Tremblay, V., \& Dion, J. (2020). Stress experienced during the COVID-19 pandemic [Brochure]. Université de Montréal and Université du Québec à Chicoutimi. https://www.sophiebergeron.ca/images/presaj/Infographic_Stress_and_Pandemic_2020_ EN.pdf.

Cloutier, R., \& Drapeau, S. (2008). Psychologie de l'adolescence. Chenelière Éducation.

Costa, N. M., Weems, C. F., \& Pina, A. A. (2009). Hurricane Katrina and youth anxiety: The role of perceived attachment beliefs and parenting behaviors. Journal of Anxiety Disorders, 23(7), 935-941. https://doi.org/10.1016/j.janxdis.2009.06.002 
Dennis, M. L., Chan, Y. F., \& Funk, R. R. (2006). Development and validation of the GAIN Short Screener (GSS) for internalizing, externalizing and substance use disorders and crime/violence problems among adolescents and adults. American Journal on Addictions, 15, 80-91.

Derogatis, L. R., \& Melisaratos, N. (1983). The brief symptom inventory: An introductory report. Psychological Medicine, 13, 595-605. https://doi.org/10.1017/S0033291700048017

Douilliez, C., \& Hénot, E. (2013). Mesures du perfectionnisme chez l'adolescent: Validation des versions francophones de deux questionnaires. Canadian Journal of Behavioural Science/revue Canadienne Des Sciences Du Comportement, 45(1), 64

Dozois, D. J. A., \& Mental Health Research Canada. (2020). Anxiety and depression in Canada during the COVID-19 pandemic: A national survey. Canadian Psychology, 62(1), 136-142.

Dumas, J. E. (2013). Psychopathologie de l'enfant et de l'adolescent (4th ed.). De Boeck.

Dumas, T. M., Ellis, W. E., \& Litt, D. M. (2020). What does adolescent substance use look like during the COVID-19 pandemic? Examining changes in frequency, social contexts, and pandemic-related predictors. Journal of Adolescent Health, 67, 354-361. https://doi.org/10.1016/j.jadohealth.2020. 06.018

Eccles, J. S., Midgley, C., Wigfield, A., Miller Buchanan, C., Reuman, D., Flanagan, C., \& MacIver, D. (1993). Development during adolescence: The impact of stage-environment fit on young adolescents' experiences in schools and families. The American Psychologist, 48(2), 90-101.

Ellis, W. E., Dumas, T. M., \& Forbes, L. M. (2020). Physically isolated but socially connected: Psychological adjustment and stress among adolescents during the initial COVID-19 crisis. Canadian Journal of Behavioural Science, 52(3), 177-187. https://doi.org/10.1037/cbs0000215

Fernández-Berrocal, P., Cabello, R., Castillo, R., \& Extremera, N. (2012). Gender differences in emotional intelligence: The mediating effect of age. Behavioral Psychology, 20(1), 77-89.

Flett, G., Hewitt, P. L., Boucher, D. J., Davidson, L. A., \& Munro, Y. (2000). The Child-Adolescent Perfectionism Scale: Development, Validation, and Association with Adjustment. [Unpublished manuscript].

Frippiat, D., \& Marquis, N. (2010). Les enquêtes par Internet en sciences sociales: Un état des lieux. Population, 65(2), 309-338. https://doi.org/10.3917/popu.1002.0309

Généreux, M., Dallaire, J.-S., Haichin, K., \& Leflej, N. (2021). Dévoilement des premiers résultats de l'Enquête sur la santé psychologique des 12-25 ans [Conference session]. "Santé mentale en Estrie" webinar.

Généreux, M., Schluter, P. J., Hung, K. C., Wong, C. S., Mok, C. P. Y., O’Sullivan, T., David, M. D., Carignan, M.-E., Blouin-Genest, G., Champagne-Poirier, O., Champagne, E., Burlone, N., Qadar, Z., Herbosa, T., Ribeiro-Alves, G., Law, R., Murray, V., Chan, E. Y. Y., Pignard-Cheynel, N., ... Roy, M. (2020). One virus, four continents, eight countries: An interdisciplinary and international study on the psychosocial impacts of the COVID-19 pandemic among adults. International Journal of Environmental Research and Public Health. https://doi.org/10.3390/ijerph17228390

Godin, G. (2011). The godin-shephard leisure-time physical activity questionnaire. Health \& Fitness Journal of Canada, 4, 18-22. https://doi.org/10.14288/hfjc.v4i1.82

Goldberg, M. (2000). L'épidémiologie sans peine (2nd ed.). Presses de l'Université du Québec.

Gosselin, P. (2007). Questionnaire des cognitions reliées à l'anxiété généralisée (CAG). [Unpublished document]. Departement of psychology, Université de Sherbrooke.

Hawke, L. D. (2020). Impacts of COVID-19 on youth mental health, substance use, and well-being: A rapid survey of clinical and community samples. The Canadian Journal of Psychiatry, 65(10), 701-709. https://doi.org/10.1177/0706743720940562

Hays, R. D., \& DiMatteo, M. R. (1987). A short-form measure of loneliness. Journal of Personality Assessment, 51, 69-81. https://doi.org/10.1207/s15327752jpa5101_6

Hinton, P. R., McMurray, I., \& Brownlow, C. (2014). SPSS explained. Routledge.

Huang, Y., \& Zhao, N. (2020). Generalized anxiety disorder, depressive symptoms and sleep quality during COVID-19 outbreak in China: A web-based cross-sectional survey. Psychiatry Research. https://doi.org/10.1016/j.psychres.2020.112954

IBM Corp. Released (2017). IBM SPSS Statistics for Windows, Version 25.0. IBM Corp.

Imran, N., Zeshan, M., \& Pervaiz, Z. (2020). Mental health considerations for children \& adolescents in COVID-19 Pandemic. Pakistan Journal of Medical Sciences, 36(4), 67. https://doi.org/10.12669/ pjms.36.COVID19-S4.2759

Institut de la statistique du Québec [ISQ] (2018). Enquête québécoise sur la santé des jeunes du secondaire 2016-2017. Résultats de la deuxième édition. Gouvernement du Québec. https://statistique. quebec.ca/fr/document/enquete-quebecoise-sur-la-sante-des-jeunes-du-secondaire-2016-2017

Institut national de santé publique du Québec [INSPQ] (2020). COVID-19 - Pandémie, bien-être et santé mentale. Résultats du 16 juillet 2020. https://www.inspq.qc.ca/covid-19/sondages-attitudes-compo rtements-quebecois/sante-mentale-juillet-2020. 
Institut national de santé publique du Québec [INSPQ] (2021). Ligne du temps COVID-19 au Québec. https://www.inspq.qc.ca/covid-19/donnees/ligne-du-temps.

Kovacs, M. (1985). The Children's depression inventory (CDI). Psychopharmacology Bulletin, 21(4), 995-998.

Langley, A. K., Bergman, R. L., McCracken, J., \& Piacentini, J. C. (2004). Impairment in childhood anxiety disorders: Preliminary examination of the Child Anxiety Impact Scale-parent version. Journal of Child and Adolescent Psychopharmacology, 14, 105-114.

Martin, A., \& Gosselin, P. (2012). Propriétés psychométriques de l'adaptation francophone d'une mesure de symptômes des troubles anxieux auprès d'enfants et d'adolescents (SCARED-R). Canadian Journal of Behavioural Science, 44(1), 70-76. https://doi.org/10.1037/a0023103

Maximum City (2021). COVID-19 child and youth study: Self-Reported Healthy Behaviours, Well-Being, and School Experiences of Young. https://static1.squarespace.com/static/5a7a164dd0e628ac7b90 b463/t/6012a6d51befd9226767175c/1611835094901/COVID+Child+and+Youth+Study_+January+ 2021+Summary+Update+v2.pdf.

Maximum City (2020). COVID-19 child and youth well-being study: Canada Phase One Report. https:// static1.squarespace.com/static/5a7a164dd0e628ac7b90b463/t/5f06fa2754b02120ab39bd45/15942 92789463/COVID-19+CHILD+AND+YOUTH+WELL-BEING+STUDY-+Canada+PHASE+ ONE+Full+REPORT-2_final-2.pdf.

Meerkerk, G. J., Van Den Eijnden, R. J. J. M., Vermulst, A. A., \& Garretsen, H. F. L. (2009). The compulsive internet use Scale (CIUS): Some psychometric properties. CyberPsychology \& Behavior, 12(1), 1-6. https://doi.org/10.1089/cpb.2008.0181

Merikangas, K., Milham, M., Stingaris, A., Bromet, E., Colcombe, S., \& Zipunnikov, V. (2020). The coronavirus Health Impact Survey (CRISIS). https://github.com/nimh-mbdu/CRISIS.

Monfette, M. E., Grimard, F., Ivers, H., Blais, M. C., Lavoie, V., \& Boisvert, J. M. (2006). Validation chez les adolescents d'une version francophone d'un instrument de mesure de la peur du jugement négatif d'autrui. Canadian Journal of Behavioural Science/revue Canadienne Des Sciences Du Comportement, 38(3), 261-268. https://doi.org/10.1037/cjbs2006013

Monga, S., Birmaher, B., Chiappetta, L., Brent, D., Kaufman, J., Bridge, J., \& Cully, M. (2000). Screen for child anxiety-related emotional disorders (SCARED): Convergent and divergent validity. Depression and Anxiety, 12(2), 85-91.

Moore, S. A., Faulkner, G., Rhodes, R. E., Brussoni, M., Chulak-Bozzer, T., Ferguson, L. J., Mitra, R., O'Reilly, N., Spence, J. C., Vanderloo, L. M., \& Tremblay, M. S. (2020). Impact of the COVID-19 virus outbreak on movement and play behaviours of Canadian children and youth: A national survey. The International Journal of Behavioral Nutrition and Physical Activity. https://doi.org/10.1186/ s12966-020-00987-8

Morin, A. J. S., Moullec, G., Maiano, C., Layet, L., Just, J.-L., \& Ninot, G. (2011). Propriétés psychométriques du Center for Epidemiologic Studies Depression Scale (CES-D) sur un échantillon français d'adultes cliniques et non-cliniques. Revue D'épidémiologie Et De Santé Publique, 59(5), 327-340. https://doi.org/10.1016/j.respe.2011.03.061

Munn, Z., Twaddle, S., Service, D., Harrow, E., Okwen, P. M., Schünemann, H., \& Vandvik, P. O. (2020). Developing guidelines before, during, and after the COVID-19 pandemic. Annals of Internal Medicine, 173(12), 1012-1015. https://doi.org/10.7326/M20-4907

Muris, P., Merckelbach, H., Mayer, B., van Brakel, A., Thissen, S., Moulaert, V., \& Gadet, B. (1998). The screen for child anxiety related emotional disorders (SCARED) and traditional childhood anxiety measures. Journal of Behavior Therapy and Experimental Psychiatry, 29(4), 327-339.

Newby, J. M., O’Moore, K., Tang, S., Christensen, H., \& Faasse, K. (2020). Acute mental health response during the COVID-19 pandemic in Australia. PLOS ONE, 15, 7. https://doi.org/10.1371/journal.pone. 0236562

Newman, B. M., \& Newman, P. R. (2020). Theories of Adolescent Development. Academic Press.

Ohannessian, C. M. C., Milan, S., \& Vannucci, A. (2017). Gender differences in anxiety trajectories from middle to late adolescence. Journal of Youth and Adolescence, 46(4), 826-839. https://doi.org/10. 1007/s10964-016-0619-7

Qiu, J.-Y., Shen, B., Zhao, M., Wang, Z., Xie, B., \& Xu, Y. (2020). A nationwide survey of psychological distress among Chinese people in the COVID-19 epidemic: Implications and policy recommendations. General Psychiatry, 33, 2. https://doi.org/10.1136/gpsych-2020-100213

Robillard, R., Saad, M., Edwards, J., Solomonova, E., Pennestri, M.-H., Daros, A., Veissière, S. P. L., Quilty, L., Dion, K., Nixon, A., Phillips, J., Bhatla, R., Spilg, E., Godbout, R., Yazji, B., Rushton, C., Gifford, W. A., Gautam, M., Boafo, A., ... Kendzerska, T. (2020). Social, financial and psychological stress during an emerging pandemic: Observations from a population survey in the acute phase of COVID-19. British Medical Journal Open. https://doi.org/10.1136/bmjopen-2020-043805 
Roche, N., Tonia, T., Bush, A., Brightling, C., Kolb, M., Dinh-Xuan, A. T., Humbert, M., Simonds, A., \& Adir, Y. (2020). Guidance production before evidence generation for critical issues: The example of COVID-19. European Respiratory Review. https://doi.org/10.1183/16000617.0310-2020

Rousseau, N. (2020). Les solutions des jeunes pour optimiser leur engagement scolaire en temps de pandémie. [Conference session]. "Les jeunes face aux conséquences de la COVID-19" webinar. http:// www.chairejeunesse.ca/node/1171

Smith, J., Guimond, F.-A., Bergeron, J., St-Amand, J., Fitzpatrick, C., \& Gagnon, M. (2021). Changes in Students' Achievement Motivation in the Context of the COVID-19 Pandemic: A Function of Extraversion/Introversion? Education Sciences, 11(1). https://doi.org/10.3390/educsci11010030

Szaflarski, M., Cubbins, L. A., \& Meganathan, K. (2017). Anxiety disorders among US immigrants: The role of immigrant background and social-psychological factors. Issues in Mental Health Nursing, 38(4), 317-326. https://doi.org/10.1080/01612840.2017.1287790

Tardif-Grenier, K., Archambault, I., Dupéré, V., Marks, A. K., \& Olivier, E. (2021). Canadian adolescents' internalized symptoms in pandemic times: Sex differences and association with sociodemographic characteristics, confinement habits, and support. The Psychiatric Quarterly. https://doi.org/10.21203/ rs.3.rs-93849/v1

Taylor, J., \& Deane, F. P. (2002). Development of a short form of the Test Anxiety Inventory (TAI). The Journal of General Psychology, 129(2), 127-136.

Turgeon, L., \& Gosselin, M.-J. (2015). Les programmes préventifs en milieu scolaire auprès des enfants et des adolescents présentant de l'anxiété. Éducation Et Francophonie, 43(2), 30-49.

Vallières, E. F., \& Vallerand, R. J. (1990). Traduction et validation canadienne-française de l'Échelle de l'Estime de Soi de Rosenberg. International Journal of Psychology, 25(2), 305-316.

Wang, C., Pan, R., Wan, X., Tan, Y., Xu, L., Ho, C. S., \& Ho, R. C. (2020). Immediate psychological responses and associated factors during the initial stage of the 2019 coronavirus disease (COVID-19) epidemic among the general population in China. International Journal of Environmental Research and Public Health, 17, 5. https://doi.org/10.3390/ijerph17051729

Watson, D., \& Friend, R. (1969). Measurement of social evaluative anxiety. Journal of Consulting and Clinical Psychology, 33, 448-457.

Weems, C. F., Scott, B. G., Banks, D. M., \& Graham, R. A. (2012). Is TV traumatic for all youths? The role of preexisting posttraumatic-stress symptoms in the link between disaster coverage and stress. Psychological Science, 23(11), 1293-1297. https://doi.org/10.1177/0956797612446952

YoungMinds (2020). Coronavirus: Impact on young people with mental health needs. https://youngminds. org.uk/media/3708/coronavirus-report_march2020.pdf

YoungMinds. (2021). Coronavirus: Impact on young people with mental health needs. https://youngminds. org.uk/media/4350/coronavirus-report-winter.pdf

Publisher's Note Springer Nature remains neutral with regard to jurisdictional claims in published maps and institutional affiliations.

\section{Authors and Affiliations}

\section{Julie Lane ${ }^{1}$ - Danyka Therriault ${ }^{1}$ (D) A Audrey Dupuis ${ }^{1} \cdot$ Patrick Gosselin $^{2}$. Jonathan $\mathrm{Smith}^{3}$. Saliha Ziam ${ }^{4} \cdot$ Mathieu Roy $^{5} \cdot$ Pasquale Roberge $^{5} \cdot$ Marti Drapeau $^{6}$. Pascale Morin $^{7} \cdot$ Felix Berrigan $^{7} \cdot$ Isabelle Thibault ${ }^{8} \cdot$ Magali Dufour $^{9}$}

1 Centre RBC d'expertise Universitaire en Santé Mentale, Université de Sherbrooke, 2500 boulevard de l'Université, SherbrookeSherbrooke, QC J1K 2R1, Canada

2 Département de Psychologie, Université de Sherbrooke, Sherbrooke, QC, Canada

3 Département de l'enseignement au Préscolaire et Primaire, Université de Sherbrooke, Sherbrooke, QC, Canada

4 École des Sciences de l'administration, Université TELUQ, Québec, QC, Canada

5 Département de Médecine de Famille, Université de Sherbrooke, Sherbrooke, QC, Canada

6 Department of Educational and Counselling Psychology, McGill University, Montréal, QC, Canada 
7 Département de Kinanthropologie, Université de Sherbrooke, Sherbrooke, QC, Canada 8 Département de Psychoéducation, Université de Sherbrooke, Sherbrooke, QC, Canada

9 Département de Psychologie, Université du Québec À Montréal, Montréal, QC, Canada 